\title{
New Classification and Visual Analysis of the Patella Cartilage during Total Knee Replacement
}

\author{
Carlos Roberto Schwartsmannn, ${ }^{1,2}$, Rafael de Luca de Lucenaa,2, João Augusto Demaman Bersch ${ }^{1,2}$ \\ ${ }^{1}$ Complexo Hospitalar Santa Casa de Porto Alegre, RS, Brasil \\ ${ }^{2}$ Universidade Federal de Ciências da Saúde de Porto Alegre, RS, Brasil \\ Email: schwartsmann@santacasa.org.br, rfdldl@gmail.com, jabersch@gmail.com
}

How to cite this paper: Schwartsmann, C.R., de Luca de Lucena, R. and Bersch, J.A.D. (2021) New Classification and Visual Analysis of the Patella Cartilage during Total Knee Replacement. Open Journal of Orthopedics, 11, 341-352.

https://doi.org/10.4236/ojo.2021.1112033

Received: October 22, 2021

Accepted: December 3, 2021

Published: December 6, 2021

Copyright $\odot 2021$ by author(s) and Scientific Research Publishing Inc. This work is licensed under the Creative Commons Attribution International License (CC BY 4.0).

http://creativecommons.org/licenses/by/4.0/

\begin{abstract}
Objective: The aim of this prospective study is to evaluate how much damage the patellar cartilage presents during a total knee replacement. Methods: The damage of the articular patellar surface was analysed by visual inspection and photographs in 354 primary total knee replacements. The authors graded the degree of cartilage lesion in five groups. The cartilage status was analyzed and correlated with age, gender, side, body mass index (BMI), Kellgren-Lawrence radiographic scale and axial deviation. Results: After statistical analysis, we concluded: there was no evidence of an association between patellar arthrosis and age gender, side, weight and deformity. Conclusions: Articular cartilage was damaged in all 354 knees. Important subchondral bone exposure occurred in 274 knees (77.4\%). Obese patients had more severe patellar osteoarthritis.
\end{abstract}

\section{Keywords}

Total Knee Replacement, Knee Arthroplasty, Patella, Femoropatellar Joint, Arthroscopy, Grading Cartilage Lesions, Radiography Classification

\section{Introduction}

The management of the patellar articular surface at the time of primary total knee replacement (TKR) is controversial. According to many surgeons the main reason for not resurfacing was normal cartilage. The need of primary patellar resurfacing could be judged based on the intraoperative findings regarding the severity of patella femoral disease.

Commonly accepted indications for patellar resurfacing are rheumatoid arthritis, patellar cysts, Loss of congruence between the patella and prosthesis design 
and severity deformity.

Femoropatellar osteoarthritis is commonly diagnosed and monitored with radiography. The reliability of radiographic classification systems is poor or moderate. The preoperative radiographs underestimate the severity of knee osteoarthritis.

Arthroscopy is considered the most valid method for evaluation of cartilage lesions but the best way for grading, measure and dimension is direct visualisation. The true extent of articular cartilage damage can be better appreciated intraoperatively.

The aim of this prospective study is to evaluate how much damage the patellar cartilage presents during a total knee replacement.

\section{Methods}

After the ethics committee approved this study, we examined 320 patients between January 2019 and December 2020 who submitted to a TKR. As 34 patients underwent these procedures bilaterally, we collected data for 354 primary TKRs. All patients in the study had a primary diagnosis of osteoarthritis.

All cases of revision knee replacement, previous bone surgery around the knee and infection history were excluded. In all cases, we used prevision surgery images: plain standardised radiographs were taken in the following views: anteroposterior, lateral and skyline of the patella.

A full-length weight-bearing roentgenogram of the lower extremity was also included.

During the surgical procedure, after exposure and eversion, damage to the articular surface of the patella was analysed by visual inspection and photographs.

The damage to the articular patellar surface was analysed macroscopically by the surgeon and three assistants, who consensually graded the degree of lesion in a new classification:

Group I: signs of softening or fibrillation of the patellar cartilage.

Group II: fissure and fragmentation of less $50 \%$ of the diameter of the patellar cartilage.

Group III: erosion exposing the subchondral bone of less than $50 \%$ of the diameter of the patellar cartilage.

Group IV: subchondral bone exposing more than $50 \%$ of the diameter of the patellar cartilage.

Group V: complete subchondral bone exposure, flattening or inversion of the patellar triangle.

In spite of cartilage damage, in no cases did we replace the patella.

When necessary, osteophyte resection was achieved for articular surface regularisation and anatomical reestablishment.

Electrocautery denervation of the edges was performed circumferentially in all cases [1] [2] [3] [4].

The age of the patients ranged from 50 to 93 years, with a mean and standard deviation of $70.7 \pm 7.6$ years. 


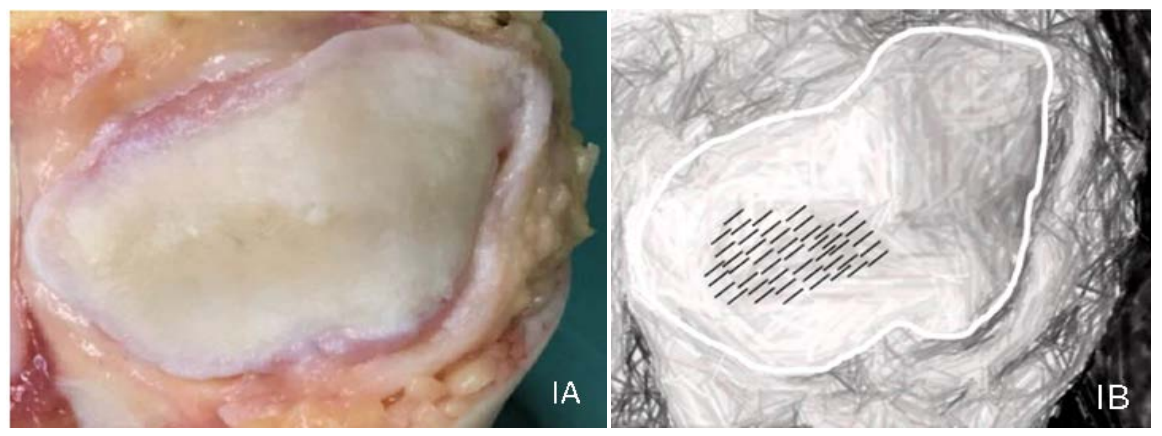

Group I. Signs of softening or fibrilation of the cartilage. (IA) Photograph of the patelar cartilage damage (Group I); (IB) Schematic drawing showing cartilage fribilation.

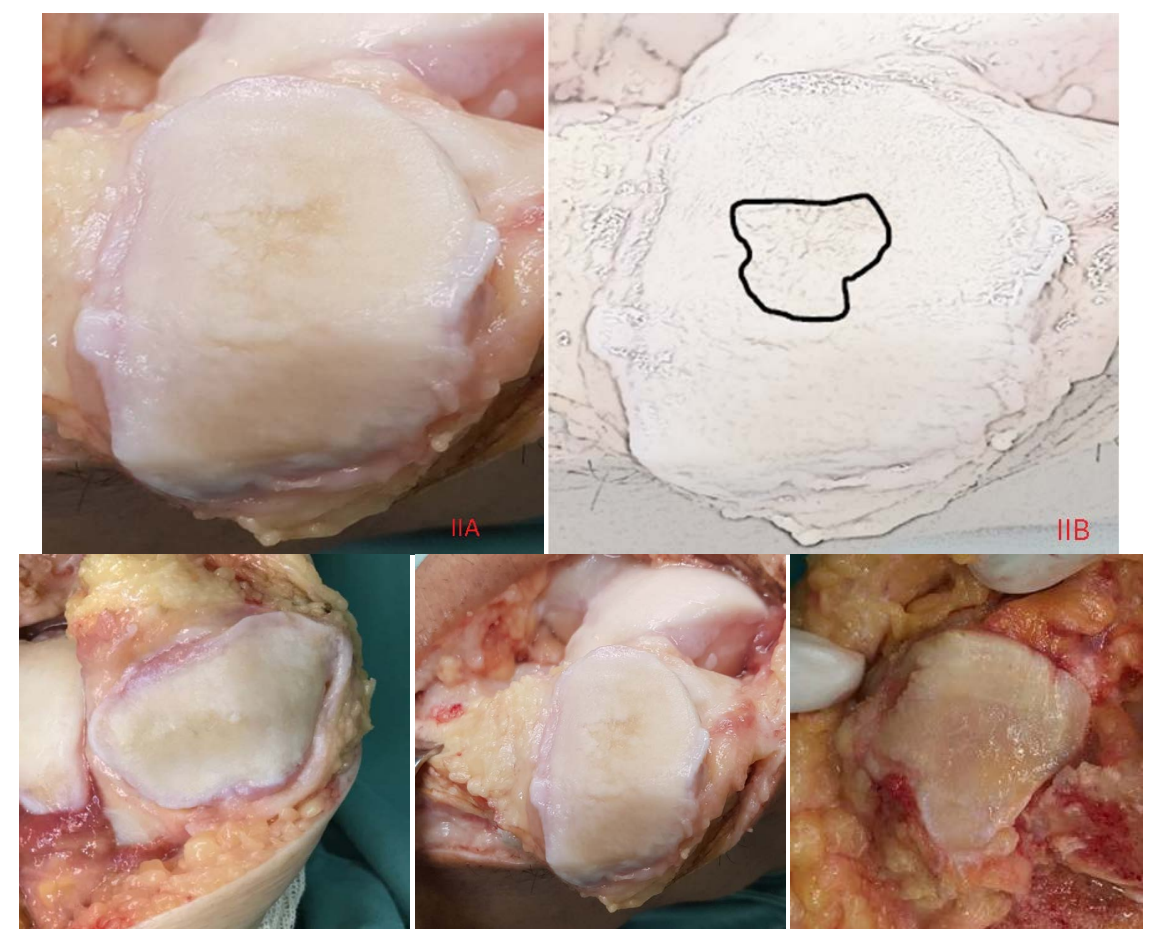

Group II. Fissure and fragmentation without subcondral bone exposing. (IIA) Photograph of the patelar cartilage damage (Group II); (IIB) Schematic drawing showing cartilage fragmentation. Three photos of different cases belonging to the Group II showing fissure and fragmentation without subcondral bone exposing.
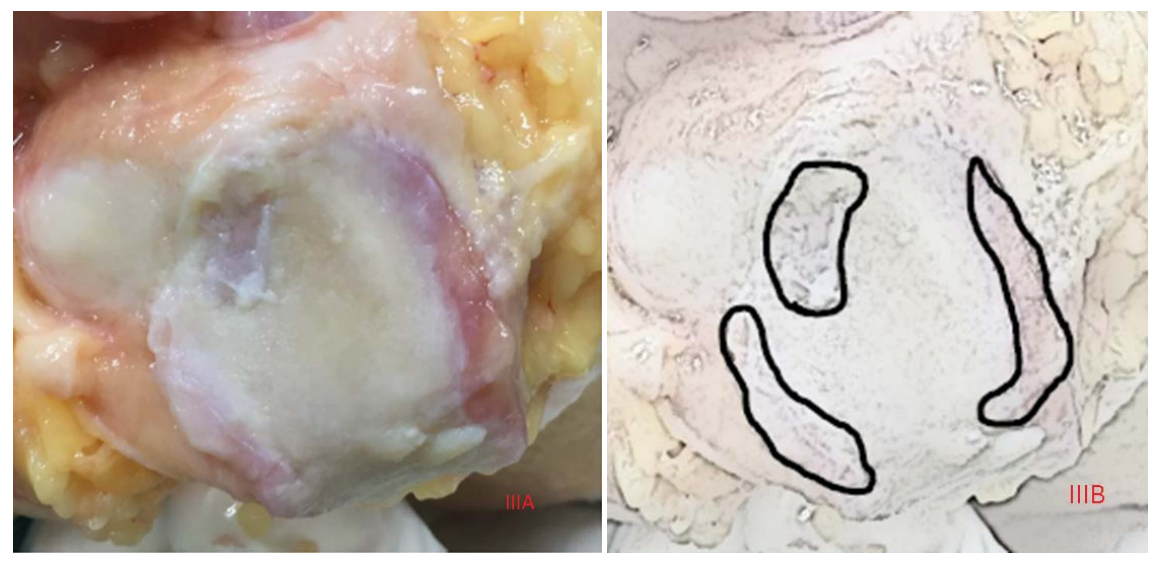

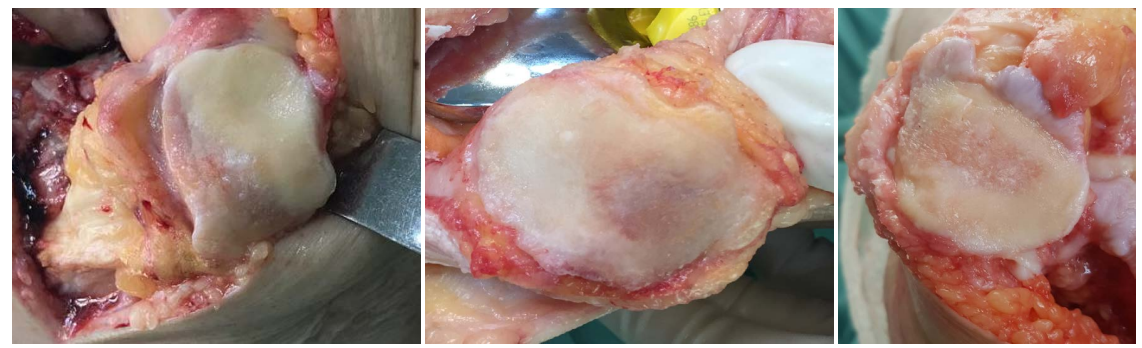

Group III. Erosion exposing the suchondral bone of less than $50 \%$ of the diameter of the cartilage. (IIIA) Photograph of the patelar cartilage damage (Group III); (IIIB) Schematic drawing showing erosion exposing subcondral bone less than $50 \%$ of the diameter of the cartilage; Three fotos belonging of Group III showing differents lesions less than $50 \%$.

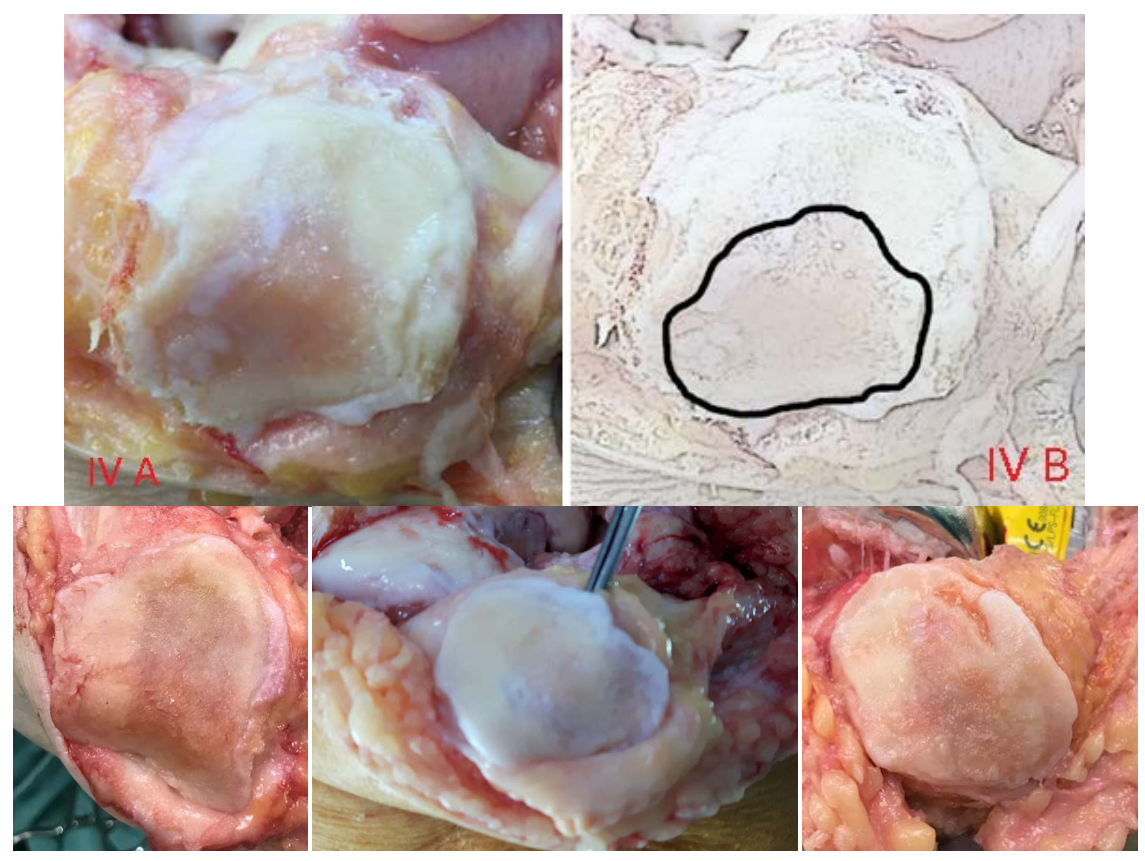

Group IV. Subchondral bone exposing more than $50 \%$ of the diameter of the patellar cartilage. (IVA) Photograph of the patelar cartilage damage (Group IV); (IVB) Schematic drawing showing subchondral bone exposing more than $50 \%$ of the diameter of patellar cartilage. Three fotos belonging of Group IV showing differents lesions more than $50 \%$ of the diameter of patellar cartilage.

In total, 251 patients (78.5\%) were female and 69 (21.5\%) were male.

The right knee was compromised in 193 cases (54.5\%) and the left knee in 161 $(45.5 \%)$.

The body mass index (BMI) ranged from 18.2 to $50.4 \mathrm{~kg} / \mathrm{m}^{2}$ with a mean of $30.5 \pm 4.7 \mathrm{~kg} / \mathrm{m}^{2}$.

Only 34 cases $(9.6 \%)$ were considered normal based on BMI $\left(18-24.9 \mathrm{~kg} / \mathrm{m}^{2}\right)$.

BMI data were: overweight $\left(25-29.9 \mathrm{~kg} / \mathrm{m}^{2}\right)$ in 136 cases $(38.4 \%)$, obese (30 $\left.34.9 \mathrm{~kg} / \mathrm{m}^{2}\right)$ in 134 cases $(37.8 \%)$ and severely obese $\left(>35 \mathrm{~kg} / \mathrm{m}^{2}\right)$ in 50 cases $(14.2 \%)$.

To radiographically grade osteoarthritis, the Kellgren-Lawrence scale was used $[5]$. 


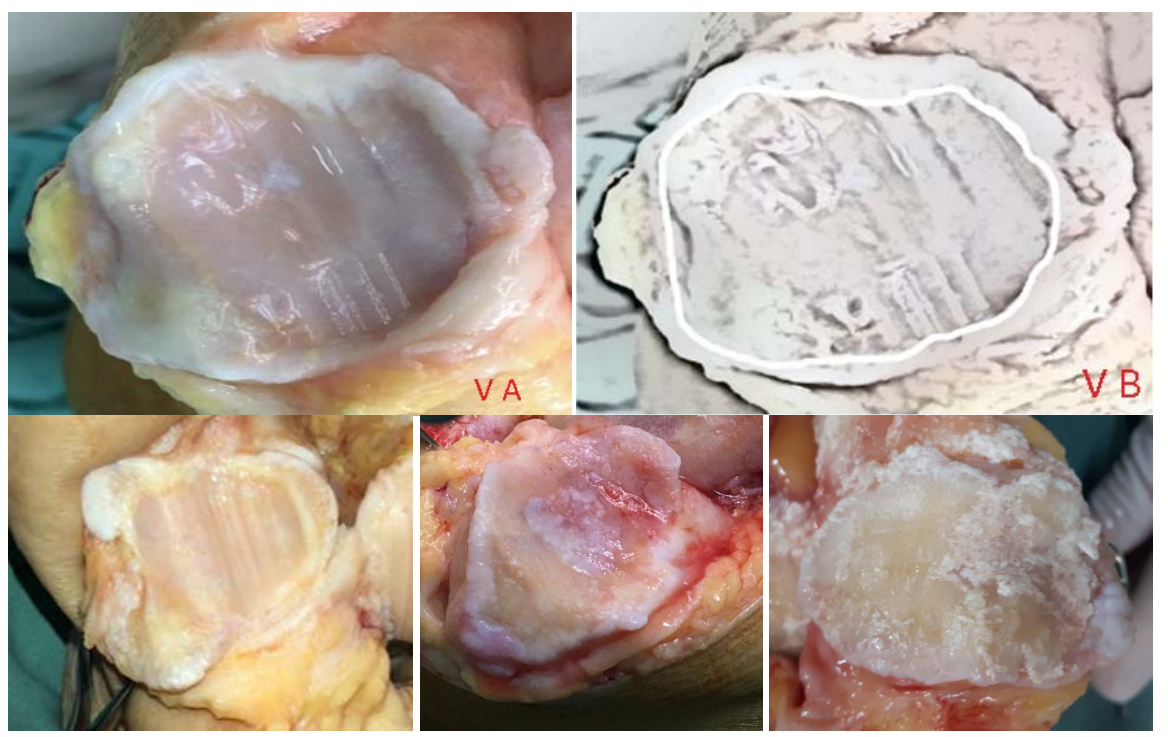

Group V. Complete subchondral bone exposure, flattening or inversion of the patellar triangle. (VA) Photograph of the patellar cartilage damage (Group V); (VB) Schematic drawing showing complete subchondral bone exposure. Three fotos belonging of Group V: showing complete disappearance of patellar cartilage.

No knees were classified as grade I or II, but 35 were considered grade III $(9.8 \%)$ and 319 were grade IV $(90.2 \%)$.

For the measurement of axial deviation, the method described by Hsu et al. [6] was used.

Only 3 cases were considered norm axis (0.8\%), 95 had genu-valgus (26.8\%) and 256 had genu-varus (72.4\%).

Mean valgus deviation was $15.6^{\circ} \pm 5.1^{\circ}$.

Mean varus deviation was $10.1^{\circ} \pm 4.8^{\circ}$.

When 354 articular patellar surfaces were analysed according to this classification, we found the following distribution: Group I: 2 cases (0.6\%); Group II: 23 cases (6.5\%); Group III: 55 cases (15.5\%); Group IV: 175 cases (49.4\%); and Group V: 99 cases (28.0\%).

When we divided cases into 2 groups according to subchondral bone exposure: Groups I-III (exposure subchondral bone less than 50\% of cartilage diameter) included 80 cases (22.6\%) and while Group IV and Group V (exposure more than 50\%) accounted for 274 cases (77.4\%).

Statistical analysis was performed using SPSS (version 21) and Fisher's exact test and Spearman's correlation coefficient where necessary.

Sociodemographic and clinical characteristics are summarized in Table 1.

\section{Results}

We found patellar cartilage damage in all cases where a total knee replacement was performed (354/354).

There was no evidence of an association between patellar arthrosis and gender $(\mathrm{p}=0.896)$. 
Table 1. Sociodemographic and clinical characteristics.

\begin{tabular}{|c|c|c|}
\hline \multicolumn{3}{|l|}{ AGE } \\
\hline Youngest & 50 years & \\
\hline Oldest & 93 years & \\
\hline Average Age & 70.7 years & \pm 7.6 \\
\hline \multicolumn{3}{|l|}{ GENDER } \\
\hline Females & 251 & $78.5 \%$ \\
\hline Males & 69 & $21.5 \%$ \\
\hline Total & 320 & $100 \%$ \\
\hline \multicolumn{3}{|l|}{ SIDE } \\
\hline Right & 193 & $54.5 \%$ \\
\hline left & 161 & $45.5 \%$ \\
\hline Total & 354 & $100 \%$ \\
\hline \multicolumn{3}{|l|}{ BODY MASS INDEX (BMI) } \\
\hline Normal & $18-24.9 \mathrm{~kg} / \mathrm{m}^{2}$ & $34(9.6 \%)$ \\
\hline Overweight & $25-29.9 \mathrm{~kg} / \mathrm{m}^{2}$ & $136(38.4 \%)$ \\
\hline Obese & $30-34.9 \mathrm{~kg} / \mathrm{m}^{2}$ & $134(37.8 \%)$ \\
\hline Severe Obese & $>35 \mathrm{~kg} / \mathrm{m}^{2}$ & $50(14.2 \%)$ \\
\hline Lower BMI & $18.2 \mathrm{~kg} / \mathrm{m}^{2}$ & \\
\hline Biggest BMI & $50.4 \mathrm{~kg} / \mathrm{m}^{2}$ & \\
\hline Average BMI & $30.5 \mathrm{~kg} / \mathrm{m}^{2}$ & $\pm 4.7 \mathrm{~kg} / \mathrm{m}^{2}$ \\
\hline \multicolumn{3}{|l|}{ KELLGREN-LAWRENCE CLASSIFICATION } \\
\hline Grade I - II & zero & \\
\hline Grade III & 35 & $(9.8 \%)$ \\
\hline Grade IV & 319 & $(90.2 \%)$ \\
\hline Total & 354 & $(100 \%)$ \\
\hline \multicolumn{3}{|l|}{ DEFORMITY } \\
\hline Normal Axis & 3 & $(0.8 \%)$ \\
\hline Genu Varus & 256 & $(72.4 \%)$ \\
\hline Genu Valgus & 95 & $(26.8 \%)$ \\
\hline Total & 354 & $(100 \%)$ \\
\hline Mean Valgus Deviation & $15.6^{\circ}$ & $\pm 5.1^{\circ}$ \\
\hline Mean Varus Deviation & $10.1^{\circ}$ & $\pm 4.8^{\circ}$ \\
\hline \multicolumn{3}{|c|}{ CLASSIFICATION OF ARTICULAR PATELLAR SURFACE DAMAGE } \\
\hline Group I & 2 & $(0.6 \%)$ \\
\hline Group II & 23 & $(6.5 \%)$ \\
\hline Group III & 55 & $(15.5 \%)$ \\
\hline Group IV & 175 & $(49.4 \%)$ \\
\hline Group V & 99 & $(28.0 \%)$ \\
\hline Less Severe Cartilage Impairment Group I + II + III & 80 & $(22.6 \%)$ \\
\hline Greater Cartilage Impairment Group IV + V & 274 & $(77.4 \%)$ \\
\hline
\end{tabular}


There was no evidence of an association between patellar arthrosis and side ( $\mathrm{p}$ $=0.850$ ).

For the analysis of age, weight and deformity, cases were divided into two groups: less severe (80/354) (Groups I-III) and more severe (Group IV and Group V) (274/354). In the second group, there was more than $50 \%$ of the subchondral bone exposed.

Spearman's correlation coefficient did not show any correlation between age and grade of arthrosis $(\mathrm{p}=0.318)$.

The same was true when divided into groups: mean age of the lower severity group (70.5 years) and higher severity group (71.5 years).

When analysing all 354 knees, there was no evidence of an association between weight and arthrosis $(\mathrm{p}=0.207)$; however, we found a significant correlation between obesity (BMI $>30)$ and more severe cases $(p=0.021)(184 / 354)$.

When analysing arthrosis with deformity in two groups, we found of more severe cases, 201/256 (78.5\%) were varus and 77/95 (76.8\%) were valgus.

No statistical association was found $(\mathrm{p}=0177)$.

\section{Discussion}

Osteoarthritis of the knee affects millions of people worldwide. It is a disabling disease resulting in pain, diminished function, and restricted motion.

The diagnosis and monitoring were performed by radiographic, tomography and magnetic resonance imaging.

Many radiographic classification systems were used in an attempt to confirm articular degenerative cartilage lesion with reliability.

The most widely used system for osteoarthritic knees are: kellgren-Lawrence [5], Ahlbäck [7], Fairbank [8], Brandt [9] and IKDC (international knee documentation committee) [10].

For analysis of only the femoropatellar joint, the Iwano [11] and Merchant [12] systems are the most commonly used.

Until now, none of the studied osteoarthritis grade classifications showed acceptable reliability [13]-[21].

The most commonly used scale for femoropatellar evaluation is the Outerbridge classification [22]. This is very simplistic and unrealistic because the worst grade (IV) only reported the subchondral bone being exposed.

Analysing this correlation with cartilage status assessed arthroscopically, they show only poor and moderate interobserver reliability [23]-[33].

Cameron [34], in a cadaver-based study, concluded: "the Outerbridge classification was moderately accurate when used to grade chondral lesions arthroscopically". Brismar [35], in a videotape study, concluded: "the arthroscopic grading of early osteoarthritic lesions in inexact”. Razak [36] found a weak correlation between radiographic and arthroscopic findings in Asian osteoarthritic knees. Spahn [37], in a multicentre survey with 301 highly experienced arthroscopists, concluded that arthroscopy was not perceived to be as reliable as a "gold stan- 
dard" for the diagnosis of cartilage lesions.

Replacement or non-replacement the patellar joint during total knee replacement remains controversial [38] [39] [40] [41] [42]. This new classification could help orthopaedic clinicians with their decision.

In this study, we found patellar cartilage lesions in all patients. Only 25 (7.1\%) were free of subchondral bone exposure.

In 329 (92.0\%), the subchondral bone was exposed to different degrees. In 274 (77.4\%), from Group IV and Group V, there was more than $50 \%$ of the subchondral bone exposed. This means that three in four patients have severe cartilage lesions. Should there be a replacement?

In 2019, we published a similar classification with 6 groups, but this has now been decreased to five [43].

Kijowski [44] correlated the radiographic findings of osteoarthritis and the arthroscopic findings of articular cartilage degeneration within the patella-femoral joint. They analysed the sensitivity for the presence of osteophytes, joint-space narrowing, subchondral sclerosis and subchondral cysts. The conclusion was that "marginal osteophytes were the most sensitive radiographic feature for the detection of articular degeneration". Osteoarthritis rarely occurred in the absence of osteophyte formation.

For this reason, in the past we included osteophyte formation in the classification. When trying to reproduce interobserver reliability testing in our orthopaedic staff and residents, the presence of osteophytes was confusing and debatable. For this reason, we now only need to know the status of the cartilage.

No relationship was found between the degree of arthrosis and gender, side, age, or deformity.

In the last paper published [43] analysing 176 total knee arthroplasties, we found an association between varus deformity and patellar arthrosis $(\mathrm{p}=0.019)$; the same was only seen for BMI $(p=0.010)$. In the present study, we only found statistical correlation in patients with a higher BMI $\left(30 \mathrm{~kg} / \mathrm{m}^{2}\right)$ and more severe cases (Group IV and Group V).

\section{Conclusion}

By visually analysing and photographing 354 patellar articular surfaces transoperatively, using this classification, we concluded:

1) Articular cartilage was damaged in all cases (100\%).

2) Important subchondral bone exposure (more than $50 \%$ of the patellar articular surface diameter) occurred in 274 knees (77.4\%) in Group IV and Group V.

3) Obese patients (BMI higher than $30 \mathrm{~kg} / \mathrm{m}^{2}$ ) had more severe patellar osteoarthritis (Group IV and Group V). Obesity is an important risk factor of patellofemoral arthrosis.

\section{Conflicts of Interest}

The authors declare no conflicts of interest regarding the publication of this paper. 


\section{References}

[1] Keblish, P.A., Varma, A.K. and Greenwald, A.S. (1994) Patellar Resurfacing, or Retention in Total Knee Arthroplasty. A Prospective Study of Patients with Bilateral Replacements. Journal of Bone and Joint Surgery, 76-B, 930-937. https://doi.org/10.1302/0301-620X.76B6.7983122

[2] van Jonbergen, H.P., Scholtes, V.A., van Kampen, A. and Poolman, R.W. (2011) A Randomised, Controlled Trial of Circumpatellar Electrocautery in Total Knee Replacement without Patellar Resurfacing. Journal of Bone and Joint Surgery, 93-B, 1054-1059. https://doi.org/10.1302/0301-620X.93B8.26560

[3] Peng, L., Luo, Y., Liu, J. and Li, Z. (2020) The Efficacy of Patellar Denervation with Electrocautery after Total Knee Replacement: A Meta-Analysis of Randomised Controlled Trials. International Journal of Surgery, 78, 126-137. https://doi.org/10.1016/j.ijsu.2020.04.049

[4] Li, T., Zhou, L., Zhuang, Q., Weng, X. and Bian, Y. (2014) Patellar Denervation in Total Knee Arthroplasty without Patellar Resurfacing and Postoperative Anterior Knee Pain: A Meta-Analysis of Randomised Controlled Trials. Journal of Arthroplasty, 29, 2309-2313. https://doi.org/10.1016/j.arth.2014.01.024

[5] Kellgren, J.H. and Lawrence, J.S. (1957) Radiological Assessment of Osteoarthrosis. Annals of the Rheumatic Diseases, 16, 494-502. https://doi.org/10.1136/ard.16.4.494

[6] Hsu, R.W., Himeno, S., Coventry, M.B. and Chao, E.Y. (1990) Normal Axial Alignment of the Lower Extremity and Load-Bearing Distribution at the Knee. Clinical Orthopaedics and Related Research, 255, 215-227. https://doi.org/10.1097/00003086-199006000-00029

[7] Ahlbäck, S. (1968) Osteoarthrosis of the Knee. A Radiographic Investigation. Acta Radiologica: Diagnosis (Stockh), 277, 7-72.

[8] Fairbank, T.J. (1948) Knee Joint Changes after Meniscectomy. Journal of Bone and Joint Surgery, 30-B, 664-670. https://doi.org/10.1302/0301-620X.30B4.664

[9] Brandt, K.D., Fife, R.S., Braunstein, E.M. and Katz, B. (1991) Radiographic Grading of the Severity of Knee Osteoarthritis: Relation of the Kellgren and Lawrence Grade to a Grade Based on Joint Space Narrowing, and Correlation with Arthroscopic Evidence of Articular Cartilage Degeneration. Arthritis \& Rheumatology, 34, 13811386. https://doi.org/10.1002/art.1780341106

[10] Hefti, F., Müller, W., Jakob, R.P. and Stäubli, H.U. (1993) Evaluation of Knee Ligament Injuries with the IKDC Form. Knee Surgery, Sports Traumatology, Arthroscopy, 1, 226-234. https://doi.org/10.1007/BF01560215

[11] Iwano, T., Kurosawa, H., Tokuyama, H. and Hoshikawa, Y. (1990) Roentgenographic and Clinical Findings of Patellofemoral Osteoarthrosis with Special Reference to its Relationship to Femorotibial Osteoarthrosis and Etiologic Factors. Clinical Orthopaedics and Related Research, 252, 190-197.

https://doi.org/10.1097/00003086-199003000-00028

[12] Merchant, A.C., Mercer, R.L., Jacobsen, R.H., Cool, C.R. (1974) Roentgenographic Analysis of Patellofemoral Congruence. Journal of Bone and Joint Surgery, 56, 13911396. https://doi.org/10.2106/00004623-197456070-00007

[13] Petersson, I.F., Boegård, T., Saxne, T., Silman, A.J. and Svensson, B. (1997) Radiographic Osteoarthritis of the Knee Classified by the Ahlbäck and Kellgren \& Lawrence Systems for the Tibiofemoral Joint in People Aged 35-54 Years with Chronic Knee Pain. Annals of the Rheumatic Diseases, 56, 493-496.

https://doi.org/10.1136/ard.56.8.493 
[14] Mehta, V.M., Paxton, L.W., Fornalski, S.X., Csintalan, R.P. and Fithian, D.C. (2007) Reliability of the International Knee Documentation Committee Radiographic Grading System. American Journal of Sports Medicine, 35, 933-935. https://doi.org/10.1177/0363546507299742

[15] Schiphof, D., Boers, M. and Bierma-Zeinstra, S.M. (2008) Differences in Descriptions of Kellgren and Lawrence Grades of knee Osteoarthritis. Annals of the Rheumatic Diseases, 67, 1034-1036. https://doi.org/10.1136/ard.2007.079020

[16] Cho, W.J., Bin, S.I., Kim, J.M., Lee, B.S., Sohn, D.W. and Kwon, Y.H. (2018) Total Knee Arthroplasty with Patellar Retention: The Severity of Patellofemoral Osteoarthritis Did Not Affect the Clinical and Radiographic Outcomes. Journal of Arthroplasty, 33, 2136-2140. https://doi.org/10.1016/j.arth.2018.02.075

[17] Köse, Ö., Acar, B., Çay, F., Yilmaz, B., Güler, F. and Yüksel, H.Y. (2018) Inter- and Intraobserver Reliabilities of Four Different Radiographic Grading Scales of Osteoarthritis of the Knee Joint. Journal of Knee Surgery, 31, 247-253.

https://doi.org/10.1055/s-0037-1602249

[18] Weidow, J., Cederlund, C.G., Ranstam, J. and Kärrholm, J. (2006) Ahlbäck Grading of Osteoarthritis of the Knee: Poor Reproducibility and Validity Based on Visual Inspection of the Joint. Acta Orthopaedica, 77, 262-266.

https://doi.org/10.1080/17453670610046000

[19] Niskanen, R.O., Paavilainen, P.J., Jaakkola, M. and Korkala, O.L. (2001) Poor Correlation of Clinical Signs with Patellar Cartilaginous Changes. Arthroscopy, 17, $307-$ 310. https://doi.org/10.1053/jars.2001.21240

[20] Abdelaziz, H., Balde, O.M., Citak, M., Gehrke, T., Magan, A. and Haasper, C. (2019) Kellgren-Lawrence Scoring System Underestimates Cartilage Damage When Indicating TKA: Preoperative Radiograph versus Intraoperative Photograph. Archives of Orthopaedic and Trauma Surgery, 139, 1287-1292. https://doi.org/10.1007/s00402-019-03223-6

[21] Keenan, O.J.F., Holland, G., Maempel, J.F., Keating, J.F. and Scott, C.E.H. (2020) Correlations between Radiological Classification Systems and Confirmed Cartilage Loss in Severe Knee Osteoarthritis. Bone \& Joint Journal, 102, 301-309. https://doi.org/10.1302/0301-620X.102B3.BJJ-2019-0337.R1

[22] Outerbridge, R.E. (1961) The Etiology of Chondromalacia Patellae. Journal of Bone and Joint Surgery, 43-B, 752-757. https://doi.org/10.1302/0301-620X.43B4.752

[23] Heng, H.Y.C., Bin Abd Razak, H.R. and Mitra, A.K. (2015) Radiographic Grading of the Patellofemoral Joint is More Accurate in Skyline Compared to Lateral Views. Annals of Translational Medicine, 3, Article No. 263.

[24] Lysholm, J., Hamberg, P. and Gillquist, J. (1987) The Correlation between Osteoarthrosis as seen on Radiographs and on Arthroscopy. Arthroscopy, 3, 161-165. https://doi.org/10.1016/S0749-8063(87)80058-0

[25] Fife, R.S., Brandt, K.D., Braunstein, E.M., Katz, B.P., Shelbourne, K.D., Kalasinski, L.A. and Ryan, S. (1991) Relationship between Arthroscopic Evidence of Cartilage Damage and Radiographic Evidence of Joint Space Narrowing in Early Osteoarthritis of the Knee. Arthritis \& Rheumatology, 34, 377-382. https://doi.org/10.1002/art.1780340402

[26] Ayral, X., Gueguen. A., Ike, R.W., Bonvarlet, J.P., Frizziero, L., Kalunian, K., Moreland, L.W., Myers, S., O’Rourke, K.S., Roos, H., Altman, R. and Dougados, M. (1998) Inter-Observer Reliability of the Arthroscopic Quantification of Chondropathy of the Knee. Osteoarthritis Cartilage, 6, 160-166.

https://doi.org/10.1053/joca.1998.0108 
[27] Wada, M., Baba, H., Imura, S., Morita, A. and Kusaka, Y. (1998) Relationship between Radiographic Classification and Arthroscopic Findings of Articular Cartilage Lesions in Osteoarthritis of the Knee. Clinical and Experimental Rheumatology, 16, 15-20.

[28] Jerosch, J., Castro, W.H., de Waal Malefijt, M.C., Busch, M. and van Kampen, A. (1997) Interobserver Variation in Diagnostic Arthroscopy of the Knee Joint. "How Really Objective Are Arthroscopic Findings?” Unfallchirurg, 100, 782-786. https://doi.org/10.1007/s001130050193

[29] Marx, R.G., Connor, J., Lyman, S., Amendola, A., Andrish, J.T., Kaeding, C., McCarty, E.C., Parker, R.D., Wright, R.W. and Spindler, K.P. (2005) Multi-Centre Orthopaedic Outcomes Network. Multi-Rater Agreement of Arthroscopic Grading of Knee Articular Cartilage. American Journal of Sports Medicine, 33, 1654-1647. https://doi.org/10.1177/0363546505275129

[30] Wright, R.W., Boyce, R.H., Michener, T., Shyr, Y., McCarty, E.C. and Spindler, K.P. (2006) Radiographs Are Not Useful in Detecting Arthroscopically Confirmed Mild Chondral Damage. Clinical Orthopaedics and Related Research, 442, 245-251. https://doi.org/10.1097/01.blo.0000167670.03197.c2

[31] AlOmran, A.S. (2009) Osteoarthritis of Knee: Correlation between Radiographic and Arthroscopic Findings. International Surgery, 94, 269-272.

[32] Lasmar, N.P., Lasmar, R.C., Vieira, R.B., de Oliveira, J.R. and Scarpa, A.C. (2015) Assessment of the Reproducibility of the Outerbridge and FSA Classifications for Chondral Lesions of the Knee. Revista Brasileira de Ortopedia, 46, 266-269. https://doi.org/10.1590/S0102-36162011000300006

[33] Lakkireddy, M., Bedarakota, D., Vidyasagar, J., Rapur, S. and Karra, M. (2015) Correlation among Radiographic, Arthroscopic and Pain Criteria for the Diagnosis of Knee Osteoarthritis. Journal of Clinical and Diagnostic Research, 9, RC04-RC07. https://doi.org/10.7860/JCDR/2015/17152.6889

[34] Cameron, M.L., Briggs, K.K. and Steadman, J.R. (2003) Reproducibility, and Reliability of the Outerbridge Classification for Grading Chondral Lesions of the Knee Arthroscopically. American Journal of Sports Medicine, 31, 83-86. https://doi.org/10.1177/03635465030310012601

[35] Brismar, B.H., Wredmark, T., Movin, T., Leandersson, J. and Svensson, O. (2002) Observer Reliability in the Arthroscopic Classification of Osteoarthritis of the Knee. Journal of Bone and Joint Surgery, 84-B, 42-47. https://doi.org/10.1302/0301-620X.84B1.0840042

[36] Razak, H.R.B.A., Heng, H.Y., Cheng, K.Y. and Mitra, A.K. (2014) Correlation between Radiographic and Arthroscopic Findings in Asian Osteoarthritic Knees. Journal of Orthopaedic Surgery (Hong Kong), 22, 155-157. https://doi.org/10.1177/230949901402200207

[37] Spahn, G., Klinger, H.M. and Hofmann, G.O. (2009) How Valid Is the Arthroscopic Diagnosis of Cartilage Lesions? Results of an Opinion Survey among Highly Experienced Arthroscopic Surgeons. Archives of Orthopaedic and Trauma Surgery, 129, 1117-1121. https://doi.org/10.1007/s00402-009-0868-y

[38] Ha, C., Wang, B., Li, W., Sun, K., Wang, D. and Li, Q. (2019) Resurfacing versus Not-Resurfacing the Patella in One-Stage Bilateral Total Knee Arthroplasty: A Prospective Randomised Clinical Trial. International Orthopaedics, 43, 2519-2527. https://doi.org/10.1007/s00264-019-04361-7

[39] (2016) Non-Resurfacing Techniques in the Management of the Patella at Total Knee Arthroplasty: A Systematic Review and Meta-Analysis. Knee, 23, 191-197. https://doi.org/10.1016/j.knee.2015.10.012 
[40] Ferreira, R.A.F.H., Mascarenhas, L.B., Salim, R., Ferreira, A.M., Fogagnolo, F. and Kfuri, M. (2018) Replacement versus Non-Replacement of the Patellar Joint Surface in Total Knee Arthroplasty. Acta Ortopédica Brasileira, 26, 175-178. https://doi.org/10.1590/1413-785220182603185026

[41] Sandiford, N.A., Alao, U., Salamut, W., Weitzel, S. and Skinner, J.A. (2014) Patella Resurfacing during Total Knee Arthroplasty: Have We Got the Issue Covered? Clinics in Orthopedic Surgery, 6, 373-378. https://doi.org/10.4055/cios.2014.6.4.373

[42] Longo, U.G., Ciuffreda, M., Mannering, N., D’Andrea, V., Cimmino, M. and Denaro, V. (2018) Patellar Resurfacing in Total Knee Arthroplasty: Systematic Review and Meta-Analysis. Journal of Arthroplasty, 33, 620-632.

https://doi.org/10.1016/j.arth.2017.08.041

[43] Schwartsmann, C.R., Spinelli, L.F., Silva, G.S., Brunelli, J.P.F., Thomaz, L.D.G.R. and Barboza, L.D. (2019) Macroscopic Analysis of the Patella Cartilage during Total Knee Replacement. MOJ Orthopedics \& Rheumatology, 11, 125-128. https://doi.org/10.15406/mojor.2019.11.00485

[44] Kijowski, R., Blankenbaker, D., Stanton, P., Fine, J. and De Smet, A. (2006) Correlation between Radiographic Findings of Osteoarthritis and Arthroscopic Findings of Articular Cartilage Degeneration within the Patellofemoral Joint. Skeletal Radiology, 35, 895-902. https://doi.org/10.1007/s00256-006-0111-7 